\title{
Benign Corrosive Stricture Excision by Lateral Pharyngotomy
}

\author{
${ }^{1}$ PK Rathore, ${ }^{2}$ Tripti Brar, ${ }^{3}$ Anoop Raj, ${ }^{4}$ Ravi Meher, ${ }^{2}$ Virad Aggarwal, ${ }^{2}$ Aditi \\ ${ }^{1}$ Director-Professor, Department of ENT, MAMC and Associated LN Hospital, New Delhi, India \\ ${ }^{2}$ Senior Resident, Department of ENT, MAMC and Associated LN Hospital, New Delhi, India \\ ${ }^{3}$ Director-Professor and Head, Department of ENT, MAMC and Associated LN Hospital, New Delhi, India \\ ${ }^{4}$ Associate Professor, Department of ENT, MAMC and Associated LN Hospital, New Delhi, India
}

Correspondence: PK Rathore, Director-Professor, Department of ENT, MAMC and Associated LN Hospital, New Delhi, India e-mail: asmita.rathore@yahoo.co.in

\section{ABSTRACT}

Benign corrosive lesion of aerodigestive tract is difficult to treat. We report a case of a 3-year-old male child who accidentally ingested acid and presented to the emergency a few hours later with difficulty in breathing and dysphagia. He was admitted and underwent a tracheotomy. A feeding jejunostomy was also done. The patient was then planned for an endoscopic examination followed by a lateral pharyngotomy. A few weeks later, a bougie dilatation of the esophageal stricture was done and the dysphagia was relieved.

Keywords: Esophageal stricture, Acid ingestion, Corrosive stricture.

\section{INTRODUCTION}

It is seen that corrosive strictures in the esophagus are not uncommon due to acid or alkali ingestion. Such ingestion may be suicidal, accidental, or in some cases homicidal. Acid ingestion usually causes corrosive damage in the stomach and al kali ingestion causes in the esophagus. ${ }^{1} \mathrm{H}$ ow ever, this is not al ways true. The extent of damage depends on the substance ingested, the quantity and the duration of exposure. ${ }^{2}$ Treatment consists of emergency management followed later by an endoscopic examination and then surgical treatment to restore the physiological functions of the aerodigestive tract.

\section{CASE REPORT}

A 3-year-old male child presented to the ENT emergency with complaints of difficulty in breathing and dysphagia after accidental acid ingestion. The accident occurred because the acid was stored in a bottle of a cola drink by the mother. The onset of symptoms was immediate. The patient was immediately rehydrated and the airway was secured by doing an emergency tracheotomy. A fter the patient's condition was stabilized, a feeding jejunostomy was done to provide nutritional requirements.

The patient was investigated and the routine blood and urine investigations were normal. A chest radiograph was done, which was also normal. Thereafter, an endoscopic examination of the aerodigestive tract was done under general anesthesia. It reveal ed circumferential cicatrization of the oropharynx, palatal adhesions with the posterior pharyngeal wall, an epiglottis which was deformed due to scars and a stricture at the level of the cricopharynx (Fig. 1). The glottis, arytenoids, pyriform sinuses and esophagus were normal. In the same setting, a lateral pharyngotomy was done and a release of pharyngeal adhesions (nasal and oral), release of epiglottis adhesions and a nasogastric tube was inserted.

The patient was started on feeding with the nasogastric tube until two weeks when the nasogastric tube was accidentally pulled out by the patient. Thereafter, we tried starting him on oral feeds, liquids initially, but the patient had severe dysphagia and did not accept oral feeds. In an attempt to accept orally, he al so suffered from repeated aspirations. Therefore, the patient was once again taken under general anesthesia and it was seen that a stricture was present at the cricopharynx. B ougie dilatation was done by gradually increasing the size of bougies from 6 to 12. Then, a nasogastric tube was inserted. In the postoperative period, the patients was started on nasogastric feeding and also made to start taking oral feeds, to which he gradually complied,

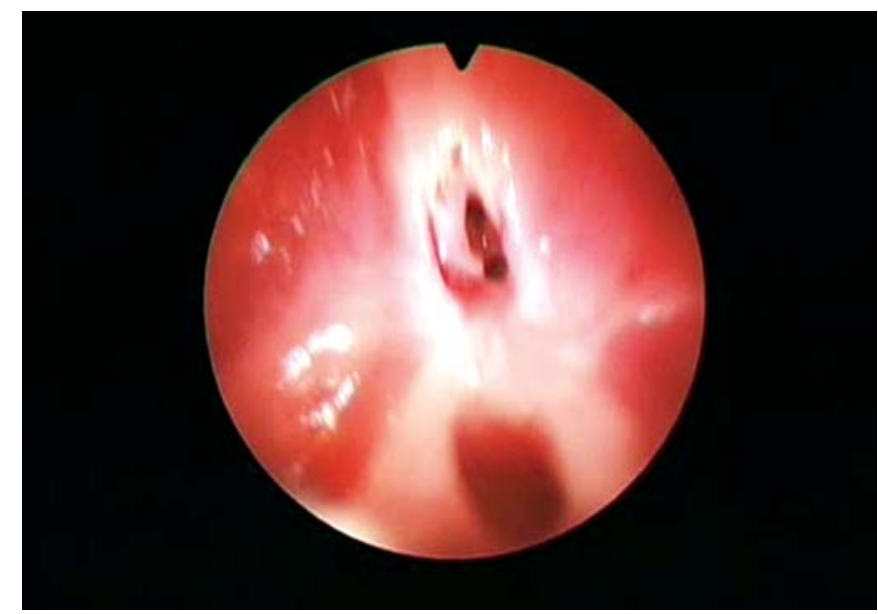

Fig. 1: Endoscopic picture showing the stricture at the level of epiglottis 
without any aspirations this time. At present, the patient is planned to be weaned off the tracheotomy and nasogastric feeding.

\section{DISCUSSION}

It is a well known fact that corrosive poisoning in children is a fairly common occurrence, especially in low income classes where the careful storage of such items is often neglected, thereby leading to accidental ingestion. ${ }^{3}$ Sometimes, there may also be homicidal or suicidal ingestion. The Holinder and Fridman classification is used to grade postcorrosive endoscopic changes in three degrees: First degree-superficial damage associated with hyperthermia, epithelial desquamation and mucous edema. Second degree- transmucous damage affecting all of the mucosal layers, followed by exudation, erosions and ulcerations. Third degree - transmural damage associated with ulcer's penetration in the deep layers of the tissue and neighboring organs. ${ }^{2}$ The degree of damage depends on the nature and quantity of the corrosive substance and also the duration of exposure. In acute poisoning, the patient is initially stabilized followed by neutralization of the substance, steroids, antibiotics and adequate nutrition. Thereafter, the patient is examined in detail by an endoscopic examination followed by dilatation of stricture or stent placement. Treatment is considered adequate when there is complete relief of dysphagia.
This may require repeated dilatation at an interval of few weeks. The del ay in the treatment may lead to fibrosis, and thus greater difficulty in dilatation. ${ }^{4}$ Recurrence rate is more common in corrosive strictures as compared to peptic strictures. The common complications may be esophageal perforation, bleeding, postdilatation stenosis. A cids cause burns more often than alkalies and acid ingestion is also more likely to cause scarring. ${ }^{5}$ Thus, such cases may require prolonged treatment and require patience on the part of the surgeon as well as the patient. A Iso, regular and prolonged follow-up is important to rule out recurrence.

\section{REFERENCES}

1. Jovancević, Dankuc D. Corrosive substance ingestions management. M ed Pregl 2008;61(Suppl 2):41-46.

2. Chibishev A, Simonovska N, ShikoleA . Post-corrosiveinjuries of upper gastrointestinal tract. Prilozi J ul 2010;31(1):297-316.

3. Contini S, Swarray-Deen A, Scarpignato C. O esophageal corrosive injuries in children: A forgotten social and health challenge in developing countries. Bull World Health Organ Dec 2009;87(12):950-54.

4. Contini S, Garatti M, Swarray-Deen A, Depetris N, Cecchini S, Scarpignato C. Corrosive oesophageal strictures in children: Outcomes after timely or delayed dilatation. Dig Liver Dis A pr 2009;41(4):263-68. E pub 2008 Sep 17.

5. Nuutinen $\mathrm{M}$, $U$ hari $\mathrm{M}, \mathrm{K}$ arvali $\mathrm{T}, \mathrm{K}$ ouval ainen $\mathrm{K}$. Consequences of caustic ingestions in children. A cta Paediatr Nov 1994; 83(11):1200-05. 